\title{
Study on Climate Impacts on Asphalt Pavement in Tibet, China
}

\author{
Chao Wang1,2, Xianxin Zhou1*, Guodong Gao' ${ }^{1}$ \\ ${ }^{1}$ Nanjing University of Information Science and Technology, Nanjing, China \\ ${ }^{2}$ Shanxi Meteorological Bureau, Taiyuan, China \\ Email: ^zhouxianxin@163.com
}

How to cite this paper: Wang, C., Zhou, X. X., \& Gao, G. D. (2019). Study on Climate Impacts on Asphalt Pavement in Tibet, China. Journal of Geoscience and Environment Protection, 7, 49-59. https://doi.org/10.4236/gep.2019.710004

Received: July 26, 2019

Accepted: October 18, 2019

Published: October 21, 2019

Copyright $\odot 2019$ by author(s) and Scientific Research Publishing Inc. This work is licensed under the Creative Commons Attribution International License (CC BY 4.0).

http://creativecommons.org/licenses/by/4.0/

\begin{abstract}
Differences in climatic conditions have a significant impact on the bearing capacity and performance of asphalt pavements. The climatic conditions in Tibet are complex. Therefore, it is necessary to establish a climate division of asphalt pavement in Tibet. In this paper, the meteorological data of 28 meteorological stations in Tibet from 1991 to 2000 were used to analyze the main climatic factors affecting the performance of highway asphalt pavement by cluster analysis. The results are as follows: 1 ) The main climatic factors affecting the performance of highway asphalt pavement in Tibet include: solar radiation, maximum temperature, minimum temperature and large temperature difference. 2) The climate zoning indicators are the average daily solar radiation daily maximum temperature, the average annual extreme maximum temperature, the annual extreme temperature, and the average annual maximum temperature for seven consecutive days. 3) Tibet can be divided into five climate zones of I-V. In summary, the geographical boundaries and indicator distribution ranges of each sub-district can provide reference for the construction of highway asphalt pavement in Tibet.
\end{abstract}

\section{Keywords}

Weather Conditions, Tibet, Asphalt Pavement Climate, China

\section{Introduction}

Asphalt is a typical temperature-sensitive material. The difference in climatic conditions has a significant impact on the bearing capacity and performance of asphalt pavement. The common rutting, cracking, aging and other diseases on asphalt pavement are closely related to climatic conditions. Li et al. (2019) analyzed the relationships among different distress types from a statistical point of view, and found that 282 asphalt pavements with semi rigid base structures in 23 regions of China were surveyed to identify 12 distress types. Cheng et al. (2018) 
investigated the feasibility of recycling waste oil shale as an alternative material into asphalt pavements in Jilin province of China, and found that the high- and low-temperature properties of asphalt materials play important roles for asphalt pavements in seasonal frozen regions. Tang et al. (2018) found that reinforced asphalt mixtures containing ROADMESH feature better properties than the other mixtures, and the field test data demonstrate that ROADMESH has the best ability to improve the structural capacity of asphalt pavement, although water permeability is reduced to some extent.

The climatic conditions in Tibet are complex, and the differences in latitude and altitude lead to multiple climatic zones in Tibet (Zhu et al., 2019; He et al., 2018; Wang \& Ma, 2018). Subtropical, warm, temperate, sub-frigid and cold zones are distributed from southeast to northwest, and the annual average temperature in Tibet is low and the daily temperature difference is large. The sun's radiation is strong, and the impact on the asphalt road is more significant (Chai et al., 2018).

Therefore, it is necessary to establish an asphalt pavement climate zone in Tibet. We firstly analyzed the applicability of Tibet in China's asphalt climate zone in this paper. Next, we selected the climate zoning indicators for the asphalt pavement in Tibet. In the end, we established a climate division of asphalt pavement in Tibet.

\section{Data and Method}

\subsection{Data}

Our study used meteorological statistics from 28 meteorological stations in Tibet, China, from 1991 to 2000. The source of information is the Chinese Meteorological Department. Meteorological elements include latitude, altitude, average maximum temperature, average minimum temperature, average daily solar radiation, average maximum wind speed, average maximum ground temperature, and average minimum ground temperature.

\subsection{Method}

Our study used a cluster analysis method (Hamed, 2019; Wang, 2017; Mcilhany \& Wiggins, 2018). It refers to the process of grouping a collection of physical or abstract objects into multiple classes of similar objects. The goal of cluster analysis is to collect data on a similar basis for classification. Clustering stems from many fields, including mathematics, computer science, statistics, biology, and economics. Many clustering techniques have been developed in different application zones. These techniques are used to describe data, measure similarities between different data sources, and classify data sources into different clusters.

\section{Results}

\subsection{Analysis of the Applicability of Tibet in China's Asphalt Climate Zone}

According to the climate division of asphalt pavement in China's current "Tech- 
nical Specifications for Highway Asphalt Pavement Construction" (JTGF40-2004), there are three asphalt subzones in Tibet, and most of the northern part of Tibet is 3 - 2 summer cool winter cold zone, northwest Goer zone. It is $2-2$ hot summer and cold winter zone, and the southeastern part of Lhasa is 2 - 3 hot summer and cold winter zone. After analysis, there are the following problems when using the asphalt climate zone of China to partition the Tibet Autonomous Region:

1) The same zoning indicators are used in Tibet and other parts of China, which cannot fully reflect the impact of special climatic conditions in Tibet on asphalt performance.

The temperature difference between day and night in Tibet is large, which is reflected on the asphalt road. The temperature difference is larger. During the annual rapid cooling period, the temperature difference between day and night is large, the internal temperature stress of the asphalt pavement is large, and the relaxation ability of the asphalt mixture caused by the low temperature at night is reduced. At low temperature, the asphalt pavement is repeatedly subjected to large temperature stresses during the rapid cooling period, and it is also more prone to temperature fatigue cracks. Therefore, when considering the climate division of asphalt pavement in Tibet, the important influence factor of large temperature difference cannot be ignored.

Tibet has a high altitude, thin air, long sunshine hours and strong solar radiation. The solar radiation on the plateau mainly affects the performance of the asphalt pavement. First, the energy of the visible part of the solar radiation is mostly absorbed by the surface and the road surface. The surface and road surface temperatures are much higher than the temperature. Due to the high solar radiation in Tibet, the temperature of the road surface is higher than that of other regions under the same temperature conditions.

Table 1 shows the difference between the highest temperature and the highest temperature in Tibet compared with the temperature difference between Tibet and other parts of China. In other zones, it is $10^{\circ} \mathrm{C}$ or more, which requires better high-temperature performance of asphalt and its mixture. Second, due to the long sunshine time on the plateau and the thin air, the ultraviolet rays passing through the atmosphere will accelerate the aging of the asphalt, the asphalt will become hard, and the asphalt will increase, which will affect the pavement performance. Therefore, the lack of solar radiation indicators is also a shortcoming of China's regulation of the Tibet asphalt climate division.

2) The number of divisions is small, and it is impossible to fully divide the use conditions of asphalt pavements in different parts of Tibet. Tibet has a large zone and complex climatic and environmental conditions. In China's asphalt pavement climate division, Tibet has only three sub-districts, and the zone of 2 2 summer hot winter and cold regions is very small. This study is from $2-3$ hot summer and cold winter zones. Two meteorological stations were selected for comparison with 3 - 2 summer cool winter zone. Both Chayu and Lhasa belong to the 2 - 3 hot summer and cold winter zone. Pali and Gertse belong to the 3 - 2 
summer cool winter zone. Table 2 lists the meteorological data of the four weather stations for 10 years.

According to the information in the table, the average maximum temperature difference between Lhasa and Chayu is $2.23^{\circ} \mathrm{C}$, the average minimum temperature is $8.82^{\circ} \mathrm{C}$, and the maximum temperature of the solar radiation is 8.55 $\mathrm{MJ} \cdot \mathrm{m}^{-2}$. In terms of minimum temperature and solar radiation, these two regions have very obvious differences should not be classified in the same climate zone. The average maximum temperature difference between Pali and Gertse is $8.02^{\circ} \mathrm{C}$, the lowest temperature is $5.28^{\circ} \mathrm{C}$, the maximum solar radiation is 8.36 $\mathrm{MJ} \cdot \mathrm{m}^{-2}$, and the average maximum temperature is $10.36^{\circ} \mathrm{C}$. It should not be classified into the same climate zone. It can be seen that the regional division of the asphalt pavement climate in China is relatively rough, and it is impossible to distinguish the climatic environment in which the asphalt pavement is located.

Table 1. Comparison of temperature between Tibet and other parts of China.

\begin{tabular}{cccc}
\hline Location & $\begin{array}{c}\text { Average maximum ground } \\
\text { temperature }\left({ }^{\circ} \mathrm{C}\right)\end{array}$ & $\begin{array}{c}\text { Average maximum } \\
\text { temperature }\left({ }^{\circ} \mathrm{C}\right)\end{array}$ & $\begin{array}{c}\text { Difference } \\
\left({ }^{\circ} \mathrm{C}\right)\end{array}$ \\
\hline Lhasa & 68.90 & 28.03 & 40.87 \\
Shigatse & 67.25 & 26.54 & 40.71 \\
Nakchu & 62.15 & 21.34 & 40.81 \\
Shiquan River & 64.56 & 25.39 & 39.17 \\
Nyingchi & 61.48 & 27.60 & 33.88 \\
Chamdo & 65.27 & 30.15 & 35.12 \\
Harbin & 58.36 & 34.31 & 24.05 \\
Tianjin & 62.69 & 37.12 & 25.57 \\
Beijing & 61.03 & 37.39 & 23.64 \\
Wuhan & 63.50 & 37.54 & 25.96 \\
Chengdu & 58.74 & 34.88 & 23.86 \\
Fuzhou & 67.24 & 38.32 & 28.92 \\
\hline
\end{tabular}

Table 2. Comparison of temperature between Tibet and other parts of China.

\begin{tabular}{ccccccccc}
\hline Location & $\begin{array}{c}\text { Latitude } \\
\left({ }^{\circ}\right)\end{array}$ & $\begin{array}{c}\text { Altitude } \\
(\mathrm{m})\end{array}$ & $\begin{array}{c}\text { Average } \\
\text { maximum } \\
\text { temperature } \\
\left({ }^{\circ} \mathrm{C}\right)\end{array}$ & $\begin{array}{c}\text { Average } \\
\text { low } \\
\text { temperature } \\
\left({ }^{\circ} \mathrm{C}\right)\end{array}$ & $\begin{array}{c}\text { Average } \\
\text { daily solar } \\
\text { radiation } \\
\left(\mathrm{MJ} / \mathrm{m}^{2}\right)\end{array}$ & $\begin{array}{c}\text { January average } \\
\text { maximum } \\
\text { wind speed } \\
(\mathrm{m} / \mathrm{s})\end{array}$ & $\begin{array}{c}\text { Average } \\
\text { maximum ground } \\
\text { temperature } \\
\left({ }^{\circ} \mathrm{C}\right)\end{array}$ & $\begin{array}{c}\text { Average minimum } \\
\text { ground } \\
\text { temperature } \\
\left({ }^{\circ} \mathrm{C}\right)\end{array}$ \\
\hline Chayu & 28.39 & 2327 & 30.26 & -3.86 & 13.50 & 0.119 & 59.46 & -8.44 \\
Lhasa & 29.43 & 3658 & 28.03 & -12.68 & 22.05 & 0.177 & 62.35 & -19.44 \\
Pali & 27.44 & 4301 & 16.45 & -24.27 & 16.12 & 0.293 & 50.33 & -30.77 \\
Gertse & 32.09 & 4700 & 24.47 & -30.99 & 24.48 & 0.358 & 60.69 & -33.35 \\
\hline
\end{tabular}




\subsection{Selection of Climate Zoning Indicators for Tibet Asphalt Pavement}

The zoning indicator is the main basis for zoning, and it is also a tool for description of difference and similarity. The rationality of index selection directly affects the rationality of zoning. Asphalt pavement climate zoning is to partition the climatic conditions that affect the applicable performance of asphalt pavement. The zoning indicators should fully reflect the corresponding climatic conditions or climatic processes that affect pavement performance.

In view of the analysis of the climate factors affecting asphalt pavement and the special natural climatic conditions in Tibet, this study believes that in the climate impact zone of asphalt pavement in Tibet, the factors affecting solar radiation, high temperature, low temperature and poor temperature should be considered. According to the characteristics of each influencing factor, the corresponding regional indicators are proposed.

First of all, we give solar radiation indicators. The photoaging of asphalt pavement under solar radiation is a long-term process. The solar radiation index that affects the photoaging of asphalt pavement should adopt the total amount or average value of solar radiation in a certain period of time. In addition, the solar radiation increases the temperature of asphalt pavement. It has a significant effect, and the influence of solar radiation on aging and road surface temperature is the most significant in the highest temperature month. Therefore, this section selects the total amount of solar radiation daily average temperature $\left(\mathrm{MJ} \cdot \mathrm{m}^{-2} \cdot \mathrm{day}^{-1}\right)$ as a description indicator.

$$
R_{\text {max,month,mean }}=\frac{1}{n} \sum_{i=1}^{n} R_{\text {max,month, mean }, i}
$$

where, $n$ is the number of years of age, and $R_{\text {max,month,mean, } i}$ is the total amount of solar radiation on the highest temperature in the $i$-th year $\left(\mathrm{MJ} \cdot \mathrm{m}^{-2} \cdot \mathrm{day}^{-1}\right)$.

Then, we give high temperature index. As far as the high temperature process is concerned, the ability of the air and the asphalt pavement to absorb solar radiation is different. In the high temperature season, the asphalt pavement temperature is often higher than the air temperature, but in the process, the high temperature process experienced by the asphalt pavement and the high temperature experienced by the outside air. The process has similarities. At the same time, external heat conditions are the main influencing factors affecting the high temperature process experienced by asphalt pavement. In the climate division of asphalt pavement, the most unfavorable conditions experienced by the asphalt pavement during use should generally be considered. Therefore, the average annual extreme maximum temperature of the sub-zone is used as an indicator to reflect the influence of the high-temperature process on the asphalt pavement.

$$
T_{\text {max }, \text { year }}=\frac{1}{n} \sum_{i=1}^{n} T_{\text {max }, \text { year }, i}
$$

where $n$ is the number of years of age, and $T_{\text {max,year, } i}$ is the extreme maximum temperature in the $i$-th year $\left({ }^{\circ} \mathrm{C}\right)$. 
Next, we give low temperature index. The extreme low temperatures experienced by asphalt pavements are mainly affected by the outside air temperature, but slightly delayed in time. Under extremely low temperature conditions, asphalt pavements are prone to low-temperature diseases such as temperature-shrinking cracks. Therefore, the sub-zone extreme minimum temperature is used as an indicator to reflect the influence of extreme low-temperature conditions on asphalt pavement.

$$
T_{\text {min }, \text { year }}=\min _{i, j}\left(T_{\min , d, i, j}\right), \quad i=1,2, \cdots, n, j=1,2, \cdots, m
$$

where $n$ is the number of years of age, $m$ is the number of days in the $i$-th year, and $T_{\min , d, i, j}$ is the minimum daily temperature $\left({ }^{\circ} \mathrm{C}\right)$ on the $j$-th day of the $i$-th year.

Finally, we give the large temperature difference indicator. The influence of temperature difference on asphalt pavement is mainly the most significant in the rapid cooling period. At this time, the minimum temperature, the highest temperature and the average temperature are gradually reduced, and the temperature difference between day and night is larger than other periods. The larger daily temperature difference will be inside the asphalt pavement. Large temperature stress is generated to cause temperature-shrinkage cracks on the asphalt pavement. The rapid cooling period is a continuous period of time. During this period, the asphalt pavement is repeatedly subjected to large temperature difference. Therefore, in order to fully reflect the impact of large temperature difference on asphalt pavement during the rapid cooling period, this paper selects the average daily temperature difference of seven consecutive days in the rapid cooling period as the index to evaluate the temperature difference.

$$
T_{\text {range, } 7 \text { day }}=\max _{j}\left(\frac{1}{n} \sum_{i=1}^{n} T_{\text {max }, m, i, j}-\frac{1}{n} \sum_{i=1}^{n} T_{\min , m, i, j}\right)
$$

where $n$ is the number of years of age, $T_{\max , m, i, j}$ is the $j$-th consecutive seven-day maximum temperature in the $i$-th year $\left({ }^{\circ} \mathrm{C}\right)$, and $T_{\text {min,m,i,j }}$ is the $j$-th consecutive seven-day minimum temperature $\left({ }^{\circ} \mathrm{C}\right)$ in the $i$-th year.

\subsection{Establishment of Climate Division of Asphalt Pavement in Tibet}

The climatic conditions affecting the performance of asphalt pavement are objective. The establishment of zoning is based on the determination of the zoning indicators, comparing the similarities and differences of each region, and merging regions with similar climatic conditions according to certain needs and principles. Different zones are drawn. This study uses the system clustering method in cluster analysis to partition, according to the analysis results to find a reasonable number of partitions and partition each weather station, and finally find the actual demarcation indicators and demarcation points of each category according to the actual situation of each partition.

To do the cluster analysis, firstly, the four indicators of 28 meteorological sta- 
tions are standardized by full-scale $-1-1$, and then the statistical analysis software SPSS 18.0 is used to analyze the statistical data of 28 meteorological stations. The clustering method uses the linkage between groups. The difference square sum method, the software gradually merges the cluster according to the squared sum of the differences between the groups of data, and displays the merge process tree diagram. The tree diagram is shown in Figure 1. The figure shows the merge process of each cluster intuitively. According to the advancement of the merge, different partition times can be determined by selecting different merge times. For example, after the first merge, it is divided into 22 zones, and the third merge is divided. For 11 partitions, there are 6 partitions after the 7th merge, 4 partitions after the 10th merge, and 3 partitions after the 15th merge.

In the asphalt pavement climate zone, too many or too few partitions are not conducive to the practical application of the project. The number of partitions is too large, the difference between the partitions is small, and the boundary of the division is not easy to determine; the number of partitions is too small to fully reflect the various zones in Tibet. The difference in the impact of climatic conditions is on asphalt pavement. Combining the above reasons with the actual climatic conditions in various parts of Tibet, it is reasonable to determine the use of the 7th combined result, because the results of the 8th merger are the same as the 7th, indicating that the results of the 7th merger are more stable, and the partitions are more stable. The difference is more obvious.

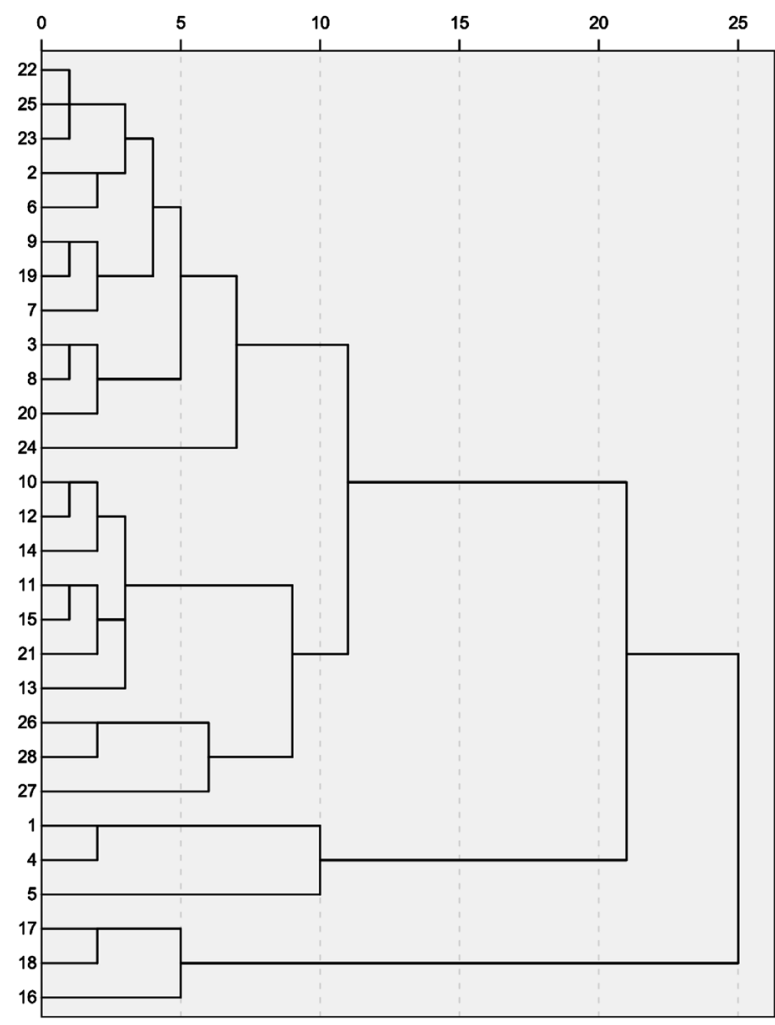

Figure 1. System cluster analysis tree. 
According to the results of the 7th merger, Nyalam is a separate subdivision. According to the actual topography and climatic conditions, Nyalam and Tsona, Pali are in the same zone as the southern slopes of the Himalayas, and the climatic conditions are similar, and in the 10th time. During the merger, the three locations were merged into the same partition. Therefore, the study classified Nyalam into Tsona and Pali divisions. The results of the final cluster analysis are shown in Table 3.

It can be seen from Table 3 that the results of the zoning are very similar to those of the administrative divisions in Tibet. Purang, Shiquan River, and the Gertse in the western Ali zone belong to the third district; Chali, Nakchu, Amdo, Shantsa, Palgon, Damshung, Sokshan in the northern Nakchu zone belong to zone II; Zogong, Tengchen, Lhorong, and Chamdo in the Chamdo zone belong to zone I; Lhasa and Nyemo in Lhasa belong to zone I, and Damshung in the North belong to zone II. Shigatse and Tingri, Shigatse, Gyantse, Zedang, Lhatse and Lhuntse in Shannan belong to zone I. Nyalam, Pali and Tsona in the south of these two zones belong to zone IV; Lingzhi, Bomi and Chayu in Nyingchi zone belong to the $\mathrm{V}$ zone. Therefore, when determining the specific zone line position of each partition, reference can be made to the administrative division boundary line, which also facilitates the application of actual engineering.

According to the results of the cluster analysis and the administrative divisions of the cities and counties to which the meteorological stations belong, the climate division of the asphalt pavement in Tibet is established, as shown in Figure 2 .

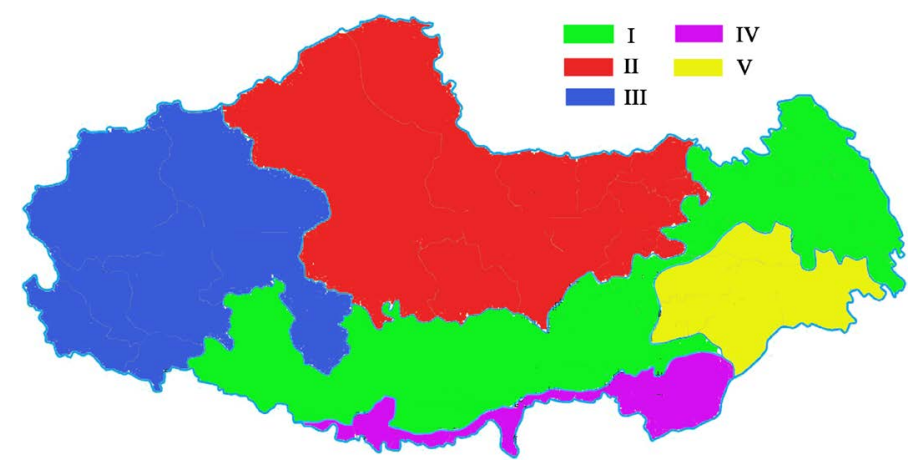

Figure 2. Climate division of asphalt pavement in Tibet.

Table 3. Partition table of each weather station.

\begin{tabular}{cc}
\hline Zone number & Weather station \\
\hline I & $\begin{array}{c}\text { Zogong, Tengchen, Lhorong, Lhuntse, Tingri, Shigatse, } \\
\text { Nyemo, Gyantse, Zedang, Lhatse, Lhasa, Chamdo }\end{array}$ \\
II & Chali, Nakchu, Amdo, Shantsa, Palgon, Damshung, Sokshan \\
III & Purang, Shiquan River, Gertse \\
IV & Tsona, Pali, Nyalam \\
V & Lingzhi, Bomi, Chayu
\end{tabular}


Then we discus partition indicator numerical distribution. According to the spatial distribution of each zoning indicator and the zoning map obtained by cluster analysis, the numerical distribution of the climatic zoning of asphalt pavement in Tibet is as follows.

Zone I: The whole is located in the south-central and northeastern parts of Tibet. The extreme values of the zoning indicators rarely appear in this zone. The average daily solar radiation daily average of the highest temperature in the years $R_{\text {max,month,mean }}$ is basically $18-22 \mathrm{MJ} \cdot \mathrm{m}^{-2} \cdot$ day $^{-1}$, the average extreme maximum temperature $T_{\text {max,year }}$ is between $23^{\circ} \mathrm{C}-27^{\circ} \mathrm{C}$, and the extreme minimum temperature $T_{\text {min,year }}$ is $-20^{\circ} \mathrm{C}--25^{\circ} \mathrm{C}$. The average temperature of the average for seven consecutive days $T_{\text {range, } 7 \text { day }}$ is between $24^{\circ} \mathrm{C}-28^{\circ} \mathrm{C}$.

Zone II: This zone is located in the north-central part of Tibet. The low temperature is the most prominent feature of the region. The average daily solar radiation day of the highest temperature $R_{\text {max,month,mean }}$ is basically distributed at $20-24 \mathrm{MJ} \cdot \mathrm{m}^{-2} \cdot \mathrm{day}^{-1}$, and the average annual extreme The maximum temperature $T_{\max , y e a r}$ is basically distributed at $18^{\circ} \mathrm{C}-21^{\circ} \mathrm{C}$, and the extreme minimum temperature $T_{\text {min,year }}$ is below $-25^{\circ} \mathrm{C}$ in the years. The average daily temperature of the continuous seven days $T_{\text {range, } 7 \text { day }}$ is distributed at $22^{\circ} \mathrm{C}-26^{\circ} \mathrm{C}$.

Zone III: Located in the northwestern part of Tibet, strong solar radiation and low temperature are the distinctive features of this region. The average daily solar radiation daily temperature of the highest temperature $R_{\text {max,month,mean }}$ is basically $24-26 \mathrm{MJ} \cdot \mathrm{m}^{-2} \cdot \mathrm{day}^{-1}$, tired. The annual average extreme maximum temperature $T_{\text {max,year }}$ is distributed at $24^{\circ} \mathrm{C}-27^{\circ} \mathrm{C}$, and the extreme minimum temperature in the years $T_{\text {min,year }}$ is below $-25^{\circ} \mathrm{C}$. The average annual temperature difference $T_{\text {range, } 7 \text { day }}$ is consistently distributed at $22^{\circ} \mathrm{C}-28^{\circ} \mathrm{C}$ for seven consecutive days.

Zone IV: Located near the Himalayas in the southern part of Tibet, the low temperature and large temperature difference are the distinctive features of the region. The average daily solar radiation day of the highest temperature $R_{\text {max,month,mean }}$ is basically below $20 \mathrm{MJ} \cdot \mathrm{m}^{-2} \cdot \mathrm{day}^{-1}$. The extreme maximum temperature $T_{\text {max,year }}$ is below $21^{\circ} \mathrm{C}$, and the extreme minimum temperature $T_{\text {min,year }}$ is $-20^{\circ} \mathrm{C}--25^{\circ} \mathrm{C}$. The average temperature of the average for seven consecutive days $T_{\text {range, }, \text { day }}$ is between $26^{\circ} \mathrm{C}-30^{\circ} \mathrm{C}$.

Zone V: Located in the southeastern part of Tibet, the relative high temperature is a prominent feature of the region. The average daily solar radiation day of the highest temperature $R_{\text {max,month,mean }}$ is basically below $18 \mathrm{MJ} \cdot \mathrm{m}^{-2} \cdot \mathrm{day}^{-1}$, and the average annual extreme maximum temperature distribution $T_{\text {max,year }}$ is at $27^{\circ} \mathrm{C}$ $30^{\circ} \mathrm{C}$, and the extreme minimum temperature $T_{\text {min,year }}$ is more than $-15^{\circ} \mathrm{C}$ in the years. The average daily temperature of the consecutive seven days $T_{\text {range, } 7 \text { day }}$ is distributed at $22^{\circ} \mathrm{C}-24^{\circ} \mathrm{C}$.

\section{Conclusion and Discussions}

China's asphalt pavement climate zoning has a single evaluation index system 
and a small number of identical subzones in Tibet. This study analyzes the main climatic factors affecting asphalt pavement performance in Tibet, such as solar radiation, high temperature, low temperature and large temperature difference. According to the characteristics of each factor, the related zoning indicators are proposed. Finally, based on the meteorological statistics of 28 meteorological stations in Tibet from 1991 to 2000, the four indicators cluster analysis was carried out. The Tibet zone was divided into five climate zones of I - V and the regional boundaries and indicators of each zone were determined and distributed.

The next step is to carry out research on the applicability of asphalt and asphalt mixture for each asphalt pavement climate zone in Tibet. Climate zone climatic conditions are a very important factor affecting the road performance of road asphalt and asphalt mixture, whether it is high-temperature rutting in summer or low temperature cracking in winter. However, China's asphalt and asphalt mixture standards do not combine the road performance and climatic conditions of asphalt pavement, resulting in poor road performance when asphalt and its mixture meet the specifications. The asphalt pavement has different degrees of early stage. Destruction phenomenon, is a defect of China's asphalt and asphalt mixture specifications. Therefore, according to the climatic characteristics of each region, combined with the road performance of asphalt and mixture to develop the corresponding asphalt and mixture standards, and select the appropriate asphalt and asphalt mixture according to this standard, the asphalt pavement has high-temperature resistance to rutting, low-temperature resistance. Cracking and good water stability, prolong the service life of the pavement, which will greatly improve the quality of asphalt pavement in China, and at the same time, it can also play a greater role in the development of the highway industry.

\section{Conflicts of Interest}

The authors declare no conflicts of interest regarding the publication of this paper.

\section{References}

Chai, M., Mu, Y., Zhang, J., Ma, W., Liu, G., \& Chen, J. (2018). Characteristics of Asphalt Pavement Damage in Degrading Permafrost Regions: Case Study of the Qinghai-Tibet Highway, China. Journal of Cold Regions Engineering, 32, 5-18. https://doi.org/10.1061/(ASCE)CR.1943-5495.0000165

Cheng, Y. C., Wang, W. S., Tan, G. J., \& Shi, C. L. (2018). Assessing High- and Low-Temperature Properties of Asphalt Pavements Incorporating Waste Oil Shale as an Alternative Material in Jilin Province, China. Sustainability, 10, 1-17. https://doi.org/10.3390/su10072179

Hamed, M. (2019). Application of Surface Water Quality Classification Models Using Principal Components Analysis and Cluster Analysis. Journal of Geoscience and Environment Protection, 7, 26-41. https://doi.org/10.4236/gep.2019.76003

He, L. F., Chen, L., Dorji, He, Z. X., Wang, X. B., Xiao, B. Y. et al. (2018). Mapping Chromite Deposits with Audio Magnetotellurics in the Luobusa Ophiolite of Southern 
Tibet. Geophysics, 83, 1-44. https://doi.org/10.1190/geo2017-0110.1

Li, J., Liu, G. Q., Yang, T., Zhou, J., \& Zhao, Y. L. (2019). Research on Relationships among Different Distress Types of Asphalt Pavements with Semi-Rigid Bases in China Using Association Rule Mining: A Statistical Point of View. Advances in Civil Engineering, 2019, 1-15. https://doi.org/10.1155/2019/5369532

Mcilhany, K., \& Wiggins, S. (2018). High Dimensional Cluster Analysis Using Path Lengths. Journal of Data Analysis and Information Processing, 6, 93-125. https://doi.org/10.4236/jdaip.2018.63007

Tang, T., Zha, X. U., Xiao, Q. M., \& Chen, Y. Q. (2018). Laboratory Characterization and Field Validation of ROADMESH-Reinforced Asphalt Pavement inChina. International Journal of Civil Engineering, 16, 299-313. https://doi.org/10.1007/s40999-016-0128-9

Wang, C. X., \& Ma, Z. F. (2018). Quasi-3-yr Cycle of Rainy Season Precipitation in Tibet Related to Different Types of ENSO during 1981-2015. Journal of Meteorological Research, 32, 181-190. https://doi.org/10.1007/s13351-018-7100-3

Wang, Z. Y. (2017). Landslide Monitoring Point Optimization Deployment Based on Fuzzy Cluster Analysis. Journal of Geoscience and Environment Protection, 5, 118-122. https://doi.org/10.4236/gep.2017.56012

Zhu, L. P., Wang, J. B., Ju, J. T., Ma, N., Zhang, Y. S., Liu, C. et al. (2019). Climatic and Lake Environmental Changes in the Serling Coregion of Tibet over a Variety of Timescales. Science Bulletin, 64, 10-12. https://doi.org/10.1016/j.scib.2019.02.016 